\title{
BARREIRAS ARQUITETÔNICAS NO PERCURSO DO DEFICIENTE FÍSICO AOS HOSPITAIS DE SOBRAL, CEARÀ $^{1}$
}

\author{
ARCHITECTURAL BARRIERS IN THE PASSAGE OF THE DEFICIENT PHYSICIST TO THE HOSPITALS OF \\ SOBRAL, CEARÁ
}

BARRERAS ARQUITECTÓNICAS EN EL PASO DEL DEFICIENTE FÍSICO A LOS HOSPITALES DE SOBRAL, CEARÁ

\section{Paulo César de Almeida ${ }^{2}$, Antonia Eliana de Araújo Aragão ${ }^{3}$, Lorita Marlena Freitag Pagliuca ${ }^{4}$, Kátia Nêyla de Freitas Macêdo ${ }^{5}$}

RESUMO: Estudo quantitativo sobre barreiras arquitetônicas no percurso do deficiente físico aos hospitais de Sobral, Ceará, com o objetivo de identificar as condições de acesso arquitetônico dos portadores de deficiência física aos quatro hospitais da mencionada cidade. Apoiado na NBR 9050 da ABNT utilizou instrumento tipo cheque-lista, cuja coleta de dados ocorreu em maio de 2004. A análise estatística constatou ausência de faixas para pedestres e apenas um apresentava rebaixamento de meio-fio em pontos estratégicos; obras públicas e particulares, desprotegidas de tapumes; calçadas com buracos e desnivelamento; metade das avenidas livres de buracos ; placas de sinalização de trânsito visíveis em três dos hospitais; percurso para a instituição sinalizado; mas não há semáforos em pontos estratégicos. Um hospital possui rebaixamento de guias; ausência de estacionamento para pessoa portadora de deficiência física. Conforme se concluiu, há barreiras arquitetônicas no percurso casa/hospital. Com isso os hospitais requerem melhores estruturas com vistas a minimizar as barreiras arquitetônicas no percurso do deficiente físico a esses serviços.

PALAVRAS CHAVE: Barreiras arquitetônicas; Pessoas portadoras de deficiência; Acesso aos serviços de saúde.

ABSTRACT: Quantitative study on architectural barriers in the passage of the deficient physicist to the hospitals of Sobral, Ceará, with the objective of mapear the access conditions architectural of the carriers of physical deficiency to the four hospitals of the mentioned city. Supported in NBR 9050 of the ABNT, it used instrument type check-list, whose collection of data occurred in May of 2004. The analysis statistics evidenced absence of bands for pedestrians and only one to show degradation of curb in strategical points; unproctected public works and particular of fences; sidewalk with holes and making uneven; half of free avenues of holes; visible plates of transit signaling in tree of hospital; passage for the signaled institution; but it does not have traffic lights in strategical points. One hospital possess degradation of guides; absence of parking for carrying person of physical deficiency. As it was concluded, has architectural barriers in the way of house / hospital.
With this the hospitals require better structures with sights to minimize the barriers architectural in the passage of the deficient physicist to these services.

KEY WORDS: Architectural accessibility; Disabled persons; Health services accessibility.

RESUMEN: El estudio cuantitativo en barreras arquitectónicas en el paso del deficiente físico a los hospitales de Sobral, Ceará con el objetivo de identificar las condiciones del acceso arquitectónico de los portadores de la deficiencia física a los cuatro hospitales de la ciudad mencionada. Apoyado en NBR 9050 del ABNT, utilizó el instrumento tipo cheque-lista, que recogida de datos ocurrió en mayo de 2004. La estadística del análisis evidenció la ausencia de las vendas para los peatones y apenas un con la degradación del encintado en los puntos estratégicos; no protección de las obras públicas y el detalle de las cercas; acera con los agujeros y desnevéis desigual; metade de las avenidas libres de los agujeros; placas visibles de señalar del tránsito en tres hospitales; paso para la institución señalada; pero no tiene semáforos en los puntos estratégicos. Uno hospital pose la degradación de las guías; ausencia de parquear para la persona que lleva de la deficiencia física. Pues fue concluido, tiene barreras arquitectónicas en el paso de la casa/del hospital. Con esto los hospitales requieren estructuras mejores con vistas reducir al mínimo las barreras arquitectónicas en el paso del físico deficiente a estos servicios.

\footnotetext{
${ }^{1}$ Parte da dissertação de mestrado defendida no Programa de Pós-Graduação em Enfermagem da Universidade Federal do Ceará (UFC) e com apoio do projeto Acessibilidade da Pessoa Portadora de Deficiência Física e ou Sensorial aos Serviços de Saúde: estudo das condições físicas e de comunicação/ Ministério da Saúde-FUNCAP. Fortaleza/CE.

2 Doutor em Estatística, Professor da Universidade Estadual do Ceará (UECE). Fortaleza/CE.

${ }^{3}$ Enfermeira, Mestre em Enfermagem Clínico-Cirúrgica, exbolsista FUNCAP. Fortaleza/CE.

${ }^{4}$ Enfermeira, Doutora em Enfermagem, Professora titular do Departamento de Enfermagem da UFC, Bolsista CNPq, Coordenadora do projeto Acessibilidade da Pessoa Portadora de Deficiência Física e ou Sensorial aos Serviços de Saúde: estudo das condições físicas e de comunicação/MS-FUNCAP. Fortaleza/CE

5 Enfermeira, Mestre em Enfermagem Clínico-Cirúrgica, bolsista CAPES. Fortaleza/CE. . Email: katyaneyla@yahoo.com.br
} 
PALABRAS CLAVE: Estructuras de acceso; Personas con discapacidad; Accesibilidad a los servicios de salud.

\section{INTRODUÇÃO}

Embora todas as pessoas possuam semelhanças e diferenças, o homem é um ser especial. Portanto cada pessoa tem características próprias, comportamento individualizado e peculiar. Estas parecem constituir regra geral na sociedade, pois enquanto diferenças essas nem sempre são alvo de interesse. Podem ser tão acentuadas que geram conseqüências prejudiciais, a exemplo do verificado com os deficientes físicos. Como é notório, elas se refletem sobre o dia-a-dia dos deficientes e causam principalmente impasses ou dificuldades para a sua locomoção e comunicação (FRANÇA \& PAGLIUCA, 2002).

Por razões culturais, freqüentemente a estética e a condição socioeconômica das pessoas são mais relevantes do que a ética, ou mesmo o conhecimento, e são mais representativas e valorizadas pela sociedade do que o reconhecimento do ser humano como pessoa.

Como deficiência entende-se toda perda ou anormalidade de uma estrutura, função psicológica, fisiológica e/ou anatômica capaz de ocasionar incapacidade para o desempenho das atividades do ser humano. A deficiência física é particularmente compreendida como alterações completas ou parciais de um ou mais segmentos do corpo, causadoras de comprometimento das funções físicas, e apresentadas em forma de paraplegia, paraparesia, monoparesia, tetraplegia, tetraparesia, triplegia, triparesia, hemiplegia, hemiparesia, amputação ou ausência de membro, paralisia cerebral, membros com deformidade congênita ou adquirida. Excetuamse, porém, as más-formações estéticas e as que não geram dificuldades para o desempenho de funções (BRASIL, 2005).

Atualmente, os portadores de deficiência são amparados por lei federal, a qual estabelece normas e direitos. Tal legislação possibilita-lhes o direito de serem incluídos socialmente. Para isto, devem superar as barreiras estruturais e sociais. Ter uma limitação não significa diminuir os direitos e deveres da pessoa, pois ela é cidadã e faz parte da sociedade como as demais (GODOY et al., 2000).

Em face da sua limitação, o portador de deficiência física pode se deparar com barreiras arquitetônicas, entre elas a ausência do rebaixamento do meio-fio; as obras no espaço público; as mesas e cadeiras de bar em calçadas; as jardineiras com saliências; as escadarias; a falta de corrimão nas escadas; a ausência de rampas; as ruas e calçadas estreitas; os declives acentuados; os pisos esburacados e/ou escorregadios; os desníveis nas calçadas; a vegetação em lugares inadequados; as placas e letreiros em locais inconvenientes; a falta de placas de advertência, de sinalização de pisos, de botoeiras nos semáforos; a altura inadequada de maçaneta, interfones e telefones; a falta de estacionamento privativo e sinalizado; a ausência de banheiros públicos e de transportes coletivos apropriados para deficientes físicos (JUNIOR-LOPES \& FARO, 2006; MASSARI, 2005;).

$\mathrm{Na}$ vida cotidiana e na trajetória profissional convive-se com pessoas portadoras de deficiência física. Entretanto, esta convivência não provoca a imediata reflexão sobre as dificuldades que encontram em seu dia-a-dia, talvez porque dependem de esforços para superar as limitações e assim minimizam as diferenças possíveis de transparecer para a comunidade na qual vivem e para a sociedade de modo geral. Como assegura a lei, as pessoas portadoras de deficiência física têm direito a tratamento adequado, e de respeito, para facilitar seu acesso e mobilização em qualquer lugar onde precisem ir, ao trabalho, às escolas, às instituições em geral e também aos hospitais.

Um olhar cuidadoso voltado para essas pessoas permite perceber a complexidade e as dificuldades por elas enfrentadas, particularmente em situação de doença, pois nem sempre os hospitais são planejados para facilitar o acesso de quem apresenta dificuldades de mobilidade física.

Frente a essa problemática as autoras deste estudo participaram do desenvolvimento de um projeto de pesquisa intitulado Acessibilidade da Pessoa Portadora de Deficiência Física e/ou Sensorial aos Serviços de Saúde: estudo das condições físicas e de comunicação. O projeto tinha por objetivo mapear as condições arquitetônicas de acesso às unidades básicas de saúde e aos hospitais das cidades de Fortaleza e Sobral. Quanto ao estudo das dificuldades de comunicação, estava adstrito aos portadores de limitação sensorial, deficiência auditiva e visual.

Nesta perspectiva, esse artigo trata de um recorte dos dados coletados nos hospitais de Sobral CE delimitando aos seguintes aspectos: o acesso casa/hospital; o acesso no interior dos hospitais; e a adequação de equipamentos e mobiliares internos.

Ante estas evidências, surgiu o interesse sobre a problemática das barreiras arquitetônicas no percurso do deficiente físico aos hospitais, pois, conforme percebido, o estudo pode contribuir para eliminar as barreiras arquitetônicas que dificultam a acessibilidade e mobilidade dos usuários aos serviços 
ALMEIDA, P. C.; ARAGÃO, A. E. A.; PAGLIUCA, L. M. F.; MACÊDO, K. N. F. Barreiras arquitetônicas no percurso do deficiente físico aos hospitais de Sobral, Cearà. Revista Eletrônica de Enfermagem, v. 08, n. 02 , p. 205 - 212 , $2006 . \quad$ Disponível em http://www.fen.ufg.br/revista/revista8 2/v8n2a05.htm

disponíveis no âmbito hospitalar. Estas contribuições podem ser extensivas, também, à assistência, ao ensino e extensão, seja no campo da enfermagem, como em outras áreas das ciências da saúde e humanas, e, até mesmo, no campo da engenharia, da arquitetura e paisagismo.

No âmbito da assistência, o estudo poderá enfatizar a utilização de uma nova abordagem na busca da promoção da saúde e qualidade de vida das pessoas portadoras de deficiência. $\mathrm{Na}$ área de ensino, esclarecer e conscientizar acerca dos fatores ambientais e comportamentais que impõem obstáculos às pessoas portadoras de deficiência física. Os resultados subsidiarão uma visão críticosociocultural e não apenas biológica, e poderão propiciar mudanças de comportamento quanto à reabilitação e integração social dos portadores de deficiência física.

Além disso, não existem no Brasil estudos que se ocupem dessa temática, sendo urgente a preocupação dos profissionais de saúde por questões dessa natureza que interferem na qualidade de vida de pessoas portadoras de deficiências físicas. A enfermagem, por sua vez tem realizado estudos sobre a deficiência física e/ou sensorial como a assistência do paciente amputado (PAGLIUCA et al., 2006), no qual foi detectada a dificuldade de acesso ao serviço de saúde e sua adaptação. O estudo de FRANÇA et al. (2004) identificou a existência de barreiras éticas da relação interpessoal entre deficiente e cuidador. A dificuldade da inclusão social das pessoas com deficiência física também foi estudada por FRANÇA \& PAGLIUCA (2002). Em outras áreas também identificamos estudos sobre a temática (LIBERMAN et al, 2006; PESSINI et al, 2006), embora na área da saúde estes ainda sejam poucos, o que indica a necessidade de investigações que tragam avanços nessa área.

Por reconhecer os direitos legítimos e legais das pessoas com limitações físicas, o objetivo deste estudo adveio da necessidade de mapear as condições arquitetônicas de acesso do portador de deficiência física aos serviços hospitalares e de averiguar as condições de acesso ao prédio.

Tem-se como suporte a Lei $\mathrm{n}^{\circ} 10.098$, de 19 de dezembro de 2000, que estabelece normas gerais e critérios básicos para a promoção da acessibilidade das pessoas portadoras de deficiência ou com mobilidade reduzida, e dá outras providências (LEIS FEDERAIS, 2000). A legislação garante às pessoas portadoras de deficiência física acesso à promoção da saúde com direito de receber visita domiciliar e atendimento diferenciado por meio de programas de saúde específicos. Para tal exige-se o desenvolvimento de programas contemplando a promoção das ações preventivas, desde o planejamento familiar, o aconselhamento genético, o parto e puerpério, a nutrição da mulher e da criança, a identificação e o controle da gestante e do feto de alto risco, a imunização, o controle das doenças metabólicas e seu diagnóstico, até o encaminhamento precoce das doenças causadoras de deficiência, recebendo quando necessário tratamento adequado (BRASIL, 2005).

Às pessoas com deficiência fica garantido o acesso à rede de serviços especializados em reabilitação e habilitação, bem como a tratamento adequado nos estabelecimentos de saúde público e privado. De acordo com a lei, se constitui crime punível, com reclusão de um a quatro anos e multa, recusar, retardar ou dificultar de alguma forma seu acesso ao serviço de saúde, negligenciando assistência médico-hospitalar e ambulatorial (BRASIL, 2005).

\section{METODOLOGIA}

Trata-se de estudo quantitativo indicado no caso de estudo exploratório para o conhecimento aprofundado de determinado problema ou objeto de pesquisa (GAUTHIER et al, 1998). Foi realizado nos quatro hospitais de Sobral, situada na Região Norte do Estado do Ceará, distante $240 \mathrm{~km}$ de Fortaleza. A cidade possui a quinta maior população do Estado, e está localizada no sertão. Tem clima quente e conta com uma área territorial de aproximadamente 1.700 $\mathrm{km}^{2}$. No setor saúde constitui referência para a Zona Norte do Estado, sendo considerado um Pólo Assistencial da Região. Os hospitais foram identificados por números de 1 a 4 , preservando-se suas identidades.

Para mapear as condições arquitetônicas de acesso das pessoas portadoras de deficiência física aos serviços hospitalares e averiguar as condições de acesso ao prédio, com base nas condições ideais estabelecidas na NBR 9050 da ABNT - Associação Brasileira de Normas Técnicas (1985) foi utilizado um instrumento no qual constava espaço para registro das condições arquitetônicas das avenidas no percurso casa/hospital, avaliando determinados aspectos. Entre estes, sobressaem as seguintes: existência de faixas para pedestres, rebaixamento de meio-fio em pontos estratégicos para tráfego de cadeiras de rodas; presença de obras públicas protegidas por tapume delimitador da área de construção; calçadas de no mínimo 1,50 metros de largura, livres de obstáculos que impeçam ou dificultem o trânsito dessas pessoas; avenidas e calçadas livres de buracos e de desnivelamentos; existência de placas de sinalização de trânsito em locais visíveis, sinalização indicativa do percurso para a instituição hospitalar, de semáforos em pontos estratégicos munidos de botoeiras de comando; escadarias e rampas externas, além de registrar se a via pública possui rebaixamento de guia distribuída por todo o percurso; estacionamento devidamente demarcado com Símbolo Internacional de Acesso e 
ALMEIDA, P. C.; ARAGÃO, A. E. A.; PAGLIUCA, L. M. F.; MACÊDO, K. N. F. Barreiras arquitetônicas no percurso do deficiente físico aos hospitais de Sobral, Cearà. Revista Eletrônica de Enfermagem, v. 08, n. 02 , p. $205 \quad$ - 212 , $2006 . \quad$ Disponível em http://www.fen.ufg.br/revista/revista8 2/v8n2a05.htm

se 0 acesso do estacionamento aos locais de atendimento ocorre sem a presença de obstáculos.

A coleta de dados foi realizada no mês de maio de 2004, por uma das pesquisadoras, enfermeira, depois de treinamento utilizando um formulário do tipo um instrumento adaptado de estudo anterior (PAGLIUCA et al, 2004). A investigação respeitou os princípios da bioética, quais sejam: autonomia, beneficência, não maleficência, justiça e eqüidade (BRASIL, 1996). Como recomendado, os dirigentes das instituições participantes do estudo tiveram a garantia do anonimato e conhecimento sobre os objetivos do trabalho, e foram esclarecidos de que poderiam desistir da pesquisa sem nenhum prejuízo. Ao concordarem em participar do estudo assinaram um termo de autorização de livre consentimento. $O$ referido projeto foi submetido à apreciação e aprovado pelo Comitê de Ética em Pesquisa do
Complexo Hospitalar da Universidade Federal do Ceará, sob protocolo 124/02 em 02 de julho de 2002. No campo de pesquisa, solicitou-se autorização por escrito aos presidentes da comissão científica de dois hospitais e aos diretores administrativos dos outros dois. Os dados foram analisados de forma descritiva e através de tabelas, após a obtenção dos dados referente a situação das avenidas no percurso casa/hospital, do acesso ao interior do hospital e da adequação de equipamentos de mobiliares internos.

\section{RESULTADOS}

As tabelas contemplam os dados dos quatro hospitais agrupados em relação à situação das avenidas no percurso casa/hospital, do acesso ao entorno do hospital e do acesso ao prédio do hospital.

Tabela 1- Distribuição do número de hospitais segundo a situação das avenidas de acesso no percurso casa/hospital. Sobral - CE, maio de 2004.

\begin{tabular}{l|c|c}
\multicolumn{1}{c|}{ SITUAÇÃO } & \multicolumn{2}{c}{ EXISTÊNCIA } \\
\cline { 2 - 3 } & \multicolumn{1}{c}{ SIM } & NÃO \\
\hline Faixas Para Pedestres & - & 4 \\
Rebaixamentos de meio-fio em pontos estratégicos & 1 & 3 \\
Obras protegidas por tapume delimitador da área de construção & - & 4 \\
Calçadas livres de obstáculos & 1 & 3 \\
Calçadas livres de buracos e desnivelamentos & - & 4 \\
Calçadas com largura mínima de 1,50m & 3 & 1 \\
Avenidas livres de buracos & 2 & 2 \\
Placas de sinalização de trânsito em locais visíveis & 3 & 1 \\
Sinalizações indicativas do percurso para a instituição hospitalar & 4 & - \\
Semáforos em pontos estratégicos munidos de botoeiras de comando & - & 4 \\
\hline
\end{tabular}

Ao se observar a Tabela 1, evidencia-se ausência de faixas de pedestres nas vias de acesso aos hospitais; apenas um apresenta rebaixamento de meio-fio em ponto estratégico; as obras em locais públicos existentes nas proximidades dos hospitais não estão protegidas por tapumes; as calçadas estão ocupadas com cadeiras, bicicletas, carrinhos de ambulantes (três) e todas têm buracos ou desnivelamento; a calçada possui a largura adequada e metade das avenidas que circundam os hospitais estão livres de buracos; há placas de sinalização de trânsito em três dos hospitais avaliados; todos os hospitais contam com sinalização indicando o percurso mas nenhum apresenta semáforo em pontos estratégicos dotados de botoeira para comando manual.

Tabela 2- Distribuição do número de hospitais segundo as condições de acesso ao entorno do hospital das pessoas portadoras de deficiência física. Sobral - CE, maio de 2004

\begin{tabular}{|c|c|c|}
\hline \multirow{2}{*}{ SITUAÇÃO } & \multicolumn{2}{|c|}{ EXISTÊNCIA } \\
\hline & SIM & NÃO \\
\hline $\begin{array}{l}\text { A via pública de acesso ao prédio possui rebaixamento de guias por todo o } \\
\text { trajeto obedecendo à inclinação transversal máxima da calçada }\end{array}$ & 1 & 3 \\
\hline $\begin{array}{l}\text { Possui estacionamento privativo para PDF devidamente demarcado com o } \\
\text { Símbolo Internacional de Acesso, número de vagas e vagas demarcadas }\end{array}$ & - & 4 \\
\hline $\begin{array}{l}\text { Os corredores de circulação e entrada de estacionamento possuem setas } \\
\text { indicativas no sentido do deslocamento com o Símbolo Internacional de Acesso } \\
\text { encaminhando para as entradas, saídas, sanitários, vagas ou locais acessíveis }\end{array}$ & - & 4 \\
\hline O percurso da vaga até a entrada do edifício é livre de obstáculos & - & 4 \\
\hline
\end{tabular}


Os dados registrados na Tabela 2 mapeiam as condições arquitetônicas nas áreas contíguas ao prédio do hospital. Como se percebe, um dos quatro hospitais possui rebaixamento de guia para acesso em todo o trajeto com inclinação transversal máxima permitida; nenhum dos locais examinados disponibiliza estacionamento privativo para carro conduzindo pessoa portadora de deficiência física, portanto, não cumpre a porcentagem recomendada pela norma; o Símbolo Internacional de Acesso indicando o trajeto de livre acesso ao portador de deficiência física ou usuário de cadeira de rodas para entrada ao prédio, saídas, sanitários vagas não foi localizado em nenhum local, ou seja, os percursos não estavam livres de obstáculos, não foi registrado sequer um banheiro adaptado para portador de limitação física ou cadeirante.

Tabela 3-Distribuição do número de hospitais segundo as condições de acesso ao prédio do hospital. Sobral -CE, maio de 2004

\begin{tabular}{|c|c|c|}
\hline \multirow{2}{*}{ SITUAÇÃO } & \multicolumn{2}{|c|}{ EXISTÊNCIA } \\
\hline & SIM & NÃO \\
\hline Rampa & 4 & - \\
\hline Escada & 3 & 1 \\
\hline O acesso possui inclinação máxima capaz de minimizar esforços da PDF & 1 & 3 \\
\hline O piso é antiderrapante & 2 & 2 \\
\hline
\end{tabular}

Com base na Tabela 3, foram observadas as seguintes situações: os quatro hospitais têm acesso por rampa; três também por escada. O que não tem escada é um edifício térreo e as rampas são de pequena inclinação. A avaliação das rampas constatou que em três hospitais o esforço a ser realizado pelo portador para subi-las seria muito grande, e algumas não atendem às exigências para acesso ao cadeirante, tanto na subida como na descida. Em dois hospitais os pisos nas rampas eram anti-derrapantes, nos outros dois, não.

\section{DISCUSSÃo}

De acordo com a NBR 9050 da ABNT (1985), as faixas de circulação nos passeios e calçadões devem estar ligadas ao leito carroçável por meio de rebaixamentos de guias, com rampas nos passeios ou quaisquer outros meios de acessibilidade, de forma que, onde se verificar o fluxo intenso de usuários, onde houver circulação acima de 21 pedestres por minuto, deve-se manter a garantia de rebaixamentos de meios-fios do lado mais distante do cruzamento, com vistas à segurança dos transeuntes. Quando não existir faixa de travessia de pedestre demarcada, os órgãos de trânsito, com jurisdição sobre a via pública, deverão ser informados para tomar as devidas medidas sobre a localização de rampas adequadas à circulação das pessoas portadoras de deficiência física.

Segundo recomendado as calçadas devem ser livres de obstáculos e ter largura mínima de 1,50 metro para circulação de duas cadeiras de rodas e as placas de sinalização e outros instrumentos que tenham projeção sobre a faixa de circulação devem situar-se à altura de 2,0 metro do piso. Além disso, nas travessias de pedestres onde houver semáforo, deve ser previsto dispositivo sonoro para atendimento aos portadores de deficiência visual. (ABNT, 1985).

Como mostra a Tabela 1, não existem faixas para pedestres. Desta forma, as pessoas precisam estar atentas ao atravessar a avenida. A existência de faixas funciona como alerta para os motoristas, motociclistas, ciclistas e pedestres, e constitui um instrumento educativo no trânsito. Em virtude do crescimento e desenvolvimento das cidades, exigemse novas decisões político-administrativas, extensivas a estas pessoas.

Ainda de acordo com a Tabela 1, só há rebaixamento de meio-fio para o acesso a um dos hospitais; nos demais, o rebaixamento existe apenas nas portas de entrada. Este resultado é compatível com os verificados nas cidades de Sobral e de Fortaleza, quando se avaliou 0 acesso às UBS (VASCONCELOS, 2003; SILVA, 2003). Encontraramse travessias sem sinalização, guias de meio-fio sem rebaixamento, ruas, avenidas e calçadas com pavimentação irregular, assim como semáforos sem botoeiras. Naquela oportunidade, somente $29,6 \%$ das UBS possuíam rebaixamento de meio-fio, enquanto apenas 7,4\% ofereciam percurso livre de obstáculos (VASCONCELOS, 2003; SILVA, 2003).

Estes resultados apontam para a escassez dos recursos de acesso da pessoa portadora de limitação física aos serviços de saúde e revelam o descaso do poder público do Município e do Estado em relação à acessibilidade de pessoas com limitações físicas.

No desenho universal, existe uma proposta de acesso. Segundo recomendado por esta proposta, é preciso haver adequação de projetos, edificações, instalações e mobiliários ao uso de pessoas portadoras de deficiência (ACESSIBILIDADE $E$ DESENHO UNIVERSAL, 1996). A conscientização quanto aos aspectos de uma arquitetura a serviço de todos, sem discriminação, deve se iniciar na formação 
do arquiteto, mas, compete à sociedade, em geral, e ao profissional de saúde, em particular, zelar pelo cumprimento dos princípios da acessibilidade. Em todos os lugares deve haver espaço para todas as pessoas.

Ao analisar as obras em vias públicas e também em particulares, conforme verificado, estas não estavam protegidas por tapumes, e muitas vezes invadiam o espaço público. Não se observa o uso deste recurso de segurança na construção civil nas proximidades dos hospitais nas cidades em estudo (ARAÚJO et al, 2002). Esta situação revela o desconhecimento dos empresários e profissionais da construção civil sobre a legislação vigente, ou ainda o descaso quanto a medidas preventivas de acidentes. Representa também a negligência dos órgãos responsáveis com a fiscalização e cumprimento da legislação, que determina a obrigatoriedade de proteção coletiva onde houver riscos de quedas de trabalhadores ou de projeção de materiais. Dessa forma, as instalações de proteção na periferia da edificação devem ser providenciadas a partir do início das construções, fechando-se com tela, instalada entre as extremidades, a qual só poderá ser retirada quando a vedação da periferia até a plataforma imediatamente superior estiver concluída.

Para ser cumprida a lei, há necessidade de se implementar o processo educativo formal e despertar a consciência de cidadania nas pessoas em geral. Rotineiramente observam-se, em especial nas grandes cidades, buracos, desníveis, raízes de árvores, carros estacionados e outros obstáculos que dificultam o trânsito de pedestres (PAGLIUCA et al, 2004).

Ao transpor esta realidade para as ruas de acesso aos hospitais estudados, é comum encontrar comércios informais nas calçadas ou estacionamentos indevidos de motocicletas, de automóveis e de bicicletas, ocupando o espaço por onde as pessoas portadoras ou não de deficiência devem transitar. As calçadas ocupadas indevidamente dificultam principalmente o acesso de quem precisa se locomover por meio de cadeiras de rodas, de muletas, de bengalas ou mesmo de outras pessoas com dificuldade de locomoção, como por exemplo, obesas e idosas.

Nenhum dos hospitais em estudo é circundado por calçadas livres de buracos e/ou desnivelamentos e, segundo aponta a Tabela 1, em apenas um dos hospitais a calçada encontra-se livre de obstáculos. Ao se projetar os espaços devem ser consideradas as condições de acessibilidade para os usuários e essas devem ser mantidas ao longo do tempo. A remoção de barreiras arquitetônicas representa um importante passo para a integração dos deficientes nos diversos setores da vida humana.

A legislação preconiza calçadas com largura de 1,50m, fundamental para a livre circulação das cadeiras de rodas. Entretanto, parece ser cultural a presença de obstáculos em calçadas de hospitais, sejam barracas de comidas ou de outros produtos. Isto, conseqüentemente, dificulta a circulação de pedestres, e os obriga a utilizar o leito das avenidas e a disputar espaço com os veículos.

No estudo, três dos hospitais são contemplados com placas de sinalização de trânsito em locais visíveis, possibilitando orientação aos usuários e minimizando os riscos de acidentes. Em quatro deles existe sinalização indicativa do percurso, a qual funciona como guia para as pessoas que buscam atendimento hospitalar. Como é notório, o cuidado humano deve contemplar todos os aspectos relacionados ao homem, e ao profissional de saúde cabe papel decisivo nas resoluções de problemas referentes à capacidade, aptidões e grau de deficiência das pessoas cuidadas (MACÊDO, 2003).

Ainda com base no estudo, alguns aspectos foram observados. Entre estes sobressaem: nas proximidades dos hospitais inexistem semáforos em pontos estratégicos munidos de botoeiras de comando e nestas áreas o trânsito costuma ser intenso. Além disso, uma das avenidas não era pavimentada. Também inexistiam: o Símbolo Internacional de Acesso, acompanhado de seta indicativa do sentido de deslocamento; as vagas demarcadas com linha contínua, na cor branca sobre o pavimento e o Símbolo Internacional de Acesso pintado no piso junto à vaga garantem segurança e conforto ao portador de deficiência física (VASCONCELOS, 2003).

O não rebaixamento de guia por todo o trajeto da calçada impossibilita as pessoas circularem livremente em cadeiras de rodas, em uso de muletas ou outros instrumentos de apoio à locomoção. Desse modo, compromete o direito de circular livremente, e cerceia a autonomia total ou parcial de terceiros.

Outra falha verificada refere-se à falta de estacionamento privativo para pessoas portadoras de deficiência. Isso requer maior atenção das autoridades, dos profissionais, das pessoas em geral e das portadoras de deficiência no sentido de se organizarem em busca dos direitos adquiridos legalmente, mas não legitimados na prática. É preciso garantir esses direitos, pois as estruturas organizacionais podem causar impactos diretos e indiretos na saúde das pessoas.

Como mostra a Tabela 3 , os quatro hospitais tinham rampas. Estas devem ser construídas junto às faixas de pedestres, demarcadas e alinhadas com o extremo da faixa de pedestre, do lado mais distante do cruzamento. Embora a largura mínima seja de 1,20 metro, o recomendável é de 1,50 metro. Ademais, a declividade desta rampa não pode exceder a $12,5 \%$ e o ponto mais baixo da rampa externa deve ficar com uma saliência de 1,5 metros junto ao meio-fio, em relação ao piso do estacionamento, para orientação da pessoa portadora de deficiência sensorial visual. Devem existir 
ALMEIDA, P. C.; ARAGÃO, A. E. A.; PAGLIUCA, L. M. F.; MACÊDO, K. N. F. Barreiras arquitetônicas no percurso do deficiente físico aos hospitais de Sobral, Cearà. Revista Eletrônica de Enfermagem, v. 08, n. 02 , p. 205 - 212 , $2006 . \quad$ Disponível em http://www.fen.ufg.br/revista/revista8 2/v8n2a05.htm

patamares no início e no final de cada segmento, com 1,20 metro na direção do movimento. A largura mínima preconizada para as escadas é de 1,20 metro. Nas áreas de circulação o fluxo principal não deve ser usado para degraus e escadas fixas com espelhos vazados ou com pisos salientes em relação ao espelho (VASCONCELOS, 2003). Estas recomendações foram observadas apenas em um dos hospitais.

O piso da rampa em dois hospitais é antiderrapante, e também em dois é constituído de materiais que podem provocar escorregões e quedas. Isto significa insegurança para as pessoas, pois, nos hospitais observados, são utilizados materiais convencionais, como piso industrial, granito, mármore, cerâmica de superfície lisa e cimento nas escadas e rampas, demonstrando insensibilidade, desconhecimento ou desinteresse em relação aos portadores de limitações e às pessoas em geral (ABNT, 1985).

\section{CONCLUSÕES}

Ao mapear as condições arquitetônicas de acesso da pessoa portadora de deficiência física aos serviços hospitalares da cidade de Sobral e averiguar as condições de acesso ao prédio, foi possível observar que a cidade, ao longo dos anos, vem crescendo em população e em desenvolvimento urbano, social, econômico, e nas áreas da saúde, da educação, do esporte e do lazer.

Entretanto requer melhor estrutura com vistas a minimizar as barreiras arquitetônicas no percurso do deficiente físico aos serviços hospitalares, de forma a otimizar as condições de acesso aos hospitais. Para facilitar 0 deslocamento de pessoas com essas dificuldades, poderiam ser adotadas medidas públicas organizacionais destinadas a lhes garantir o direito de ir e vir livremente, e, ao mesmo tempo, eliminar barreiras físicas ou atitudinais, que as impeçam de alcançar seus objetivos.

Como cidadão, cabe ao profissional da saúde a preservação do ambiente e o controle das barreiras arquitetônicas presentes no entorno do hospital, na perspectiva de minimizá-las, e proporcionar acesso sem barreiras ou empecilhos possíveis de dificultar a mobilidade das pessoas portadoras de deficiência física. Desta forma, deve este profissional lutar também por melhor uso da engenharia e da arquitetura, em benefício dos portadores de deficiência.

Eliminar as barreiras arquitetônicas que comprometem o acesso do portador de deficiência física é parte de um processo a se completar com mudanças de atitudes da sociedade e, de cada pessoa, no sentido de se adotar o comportamento inclusivo.

Como mencionado, neste estudo trata-se de um município de médio porte, mas, provavelmente, há inúmeros outros em condições semelhantes. Mantidas as devidas proporções, espera-se ter contribuído para a tomada de consciência sobre o problema e, a reflexão sobre os direitos do cidadão. E não apenas a reflexão, mas também a ação. Juntas, numa reflexão consciente, todas as pessoas se fortaleçam no dever de defender seus direitos e exercê-los na prática, em busca de uma sociedade realmente inclusiva.

\section{REFERÊNCIAS BIBLIOGRÁFICAS}

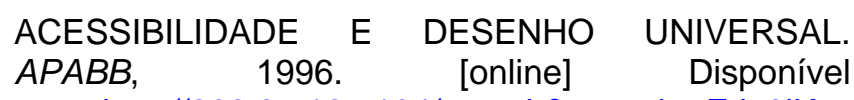

em: http://209.85.165.104/search?q=cache:Fdo8iKwt OJAJ:www.apabb.com.br/noticias/i09.htm+\%22ACES SIBILIDADE+E+DESENHO+UNIVERSAL\%22\&hl=ptBR\&ct=clnk\&cd=6\&gl=br\&client=firefox-a . [Acesso em 13 jan. 2006].

ARAÚJO, G.M.; BENITO, J.; SOUZA, C.R.C. Normas regulamentadoras comentadas: legislação e segurança de saúde no trabalho. 3. ed. Rio de Janeiro: Editora Independente, 2002. 1232 p. ASSOCIAÇÃO BRASILEIRA DE NORMAS TÉCNICAS. NBR 9050: Acessibilidade a edificações, mobiliário, espaços e equipamentos urbanos. 1985. [online] Disponível em: http://www.mi.gov.br/sedh/ct/CORDE/dpdh/corde/ ABNT/NBR9050-31052004.pdf [Acesso em 12 ago. 2003].

BRASIL. Coordenadoria Nacional para Interação da Pessoa Portadora de Deficiência. 2005 [online] Disponível

em: http://www.mj.gov.br/sedh/ct/corde/dpdh/corde/pri ncipal.asp [Acesso em 21 jan. 2006].

BRASIL. Decreto $n^{\circ}$ 3. 298, de 20 de dezembro de 1999. Disponível

em: http://www.mj.gov.br/sedh/ct/corde/dpdh/corde/de c3298.asp [Acesso em 2 mar. 2005].

BRASIL. Ministério da Saúde. Conselho Nacional de Saúde. Comissão Nacional de Ética em PesquisaCONEP. Resolução $n^{\circ}$ 196:sobre pesquisa envolvendo seres humanos. Brasília, 1996.

FRANÇA, I.S.X. de; PAGLIUCA, L.M.F. Ditos e não ditos sobre a integração social das pessoas com deficiência. Rev. RENE, Fortaleza, v.3, n.1, p.61-62, 2002.

FRANÇA, I. S. X. de; VIEIRA, N. F. C.; BARROSO, M. G. T.; VARELA, Z. M. de V. Dilemas éticos na narrativa cultural acerca dos portadores de deficiência. Rev. RENE, Fortaleza, v.5, n.2, p.101109, 2004.

GAUTHIER. J.H.M.; CABRAL, I.E.; SANTOS, I.; TAVARES, C.M.M. Pesquisa em enfermagem: novas metodologias aplicadas. Rio de Janeiro: Guanabara Koogan, 1998.

GODOY, A. et al. Cartilha da Inclusão dos Direitos da Pessoa com Deficiência. Belo Horizonte: PUC. Minas Gerais, 2000. 
JUNIOR LOPES, M.; FARO, A. C. M. Deficiências e educação inclusiva. Mundo da Saúde, Brasília, v.30, n.1, p.45-51, 2006.

LEIS FEDERAIS. Lei No. 10.098, de 19 de dezembro de 2000. [online] Disponível em: http://www.mp.pa.gov.br/leis federais.htm\#LEI\%2 ON\%BA\%2010.098,\%20DE\%2019\%20DE\%20DEZE MBRO\%20DE\%202000. [ Acesso em 22 jan. 2006]. LIBERMAN, F.; TEDESCO, S.; SAMEA, M. Habilitando a reabilitação. As ações da Terapia Ocupacional em sua integralidade. Mundo da Saúde, v.30, n.1, p.146-150, 2006.

MACÊDO, K. N de F. Acessibilidade dos portadores de deficiência visual aos serviços básicos de saúde. Monografia (graduação) Faculdade de Enfermagem, Universidade Federal do Ceará, Fortaleza, 2003.

MASSARI, S.A. A igualdade começa pelo acesso na cidade. $2005 . \quad$ [online]. Disponível em: http://209.85.165.104/search?q=cache:wC9Mc7k mla4J:www.deficiente.com.br/novo/modules.php\%3Fn ame\%3DNews\%26op\%3DNEArticle\%26sid\%3D573+ $\% 22 \mathrm{~A}+$ iqualdade+come $\%$ C3\%A7a+pelo+acesso+na+ cidade $\% 22 \& h l=p t-$

BR\&ct=clnk\&cd=1\&gl=br\&client=firefox-a [Acesso em 18 set. 2005].

PAGLIUCA, L.M.F. et al. Acessibilidade da pessoa portadora de deficiência física e/ou sensorial aos serviços de saúde: estudo das condições físicas e de comunicação. Relatório de Pesquisa da Universidade Federal do Ceará. Fortaleza, 2004.

PAGLIUCA, L. M. F.; ARAÚJO, T. L. de; ARAGÃO, A. E. de A. Pessoa com amputação e acesso ao serviço de saúde: cuidado de enfermagem fundamentado em Roy. Rev. Enfermagem UERJ, Rio de Janeiro, v.14, n.1, p.100-106, 2006.

PESSINI, L.; FERRARI, M. A. C.; GONÇALVES, M. de J. Reabilitação: de um olhar histórico aos desafios contemporâneos. Mundo saúde, Brasília, v.30, n.1,p. 5-9, 2006.

SILVA, J.F. Barreiras arquitetônicas no caminho do deficiente físico as unidades de saúde. 2003. 103 p. Monografia (Graduação) - Universidade Federal do Ceará, Fortaleza.

VASCONCELOS, L.R. Acessibilidade dos portadores de deficiência física: obstáculos no percurso casal Unidade Básica de Saúde de Sobral. 2003. 96 p. Monografia (Graduação) Departamento de Enfermagem, Universidade Federal do Ceará, Fortaleza. 